\title{
Surgical Management of Oral Squamous Cell Carcinoma in Dhaka Dental College Hospital; 31 patients.
}

\author{
Dr.Farjana sultana ${ }^{1 *}$, Dr. Md. Rezaul Karim² ${ }^{2}$ Professor Dr. Ismat Ara Haider ${ }^{3}$
}

\section{AFFILIATION}

1. Dr. Farjana Sultana , FCPS, MCPS, BDS

Assistant Professor

Department of Oral and Maxillofacial Surgery

Dhaka Dental College, Dhaka.

2. Dr. Md. Rezaul Karim, MS, BDS

Assistant Professor

Department of Oral and Maxillofacial Surgery

Colonel Malek Medical College, Manikgong.

3. Professor Dr. Ismat Ara Haider , MS ,DDS, BDS

Head, Department of Oral and Maxillofacial Surgery,

Dhaka Dental College and Hospital.

\section{Article info.}

Received: $15^{\text {th }}$ May, 2018

Accepted: $13^{\text {th }}$ August, 2018

Volume: 8, Issue-2 October, 2018

DOI: https://doi.org/10.3329/updcj.v8i2.40379

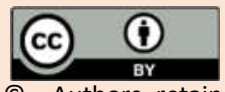

(c) Authors retain copyright and grant the journal right of first publication with the work simultaneously licensed under Creative Commons Attribution License CC - BY 4.0 that allows others to share the work with an acknowledgment of the work's authorship and initial publication in this journal.

https://creativecommons.org/licenses/by/4.0/

Publisher: Update Dental College, Dhaka, Bangladesh

Web: www.updatedentalcollege.edu.bd

E-mail: updcj@hotmail.com

\author{
* Corresponding Author \\ Dr. Farjana Sultana , FCPS, MCPS, BDS \\ Assistant Professor \\ Department of Oral and Maxillofacial Surgery \\ Dhaka Dental College, Dhaka. \\ E-mail:sultanaf19@yahoo.com
}

\section{Citation}

Dr.Farjana sultana, Dr. Md. Rezaul Karim, Professor Dr. Ismat Ara Haider - Surgical Management of Oral Squamous Cell Carcinoma in Dhaka Dental College Hospital; 31 patients, Update Dental College Journal. 2018 October; 8(2): 10-13

\section{ABSTRACT}

Cancer is a major cause of death throughout the world. Oral cancer is one of the six most frequently occurring cancer. ${ }^{1}$ In Bangladesh, the number of new cancer cases of whole body per year is about 200000 of which oral cancer is about $20 \% .^{2}$ In our neighboring country India, accounts for thirty-five percent of all newly diagnosed cancers in men. The etiology of oral cancer is well established in most instances with consumption of tobacco in any form and alcohol being the most common etiologic agents. Recently, however, exposure to the human papilloma virus has been implicated in young patients with oral carcinoma. The exact mechanism of carcinogenesis in this setting remains to be elucidated.$^{3}$

Surgery is the most well established mode of initial definitive treatment for a majority of oral cancers. The factors that affect the choice of treatment are related to the tumor and the patient. Primary site, location, proximity to bone and depth of infiltration are factors, which influence particular surgical approach. Advanced reconstructive techniques that allow free transfer of soft tissue and bone improve the functional and aesthetic outcomes following major ablative surgery .Over the course of the past thirty years there has been improvement in the overall survival of patients with oral carcinoma largely due to the improved understanding of the biology of local progression, early identification and treatment of metastatic lymph nodes in the neck and employment of adjuvant post-operative radiotherapy or chemotherapy.

Either the role of surgery in oral cancer has evolved with integration of multidisciplinary treatment approaches employing chemotherapy and radiotherapy sequentially or concurrently .Surgical expertise is required for rehabilitation of functional and aesthetic defects created by initial treatment of cancer. Thus, surgery and services of a surgeon remain central to the management of oral cancer. ${ }^{4}$

A cross sectional study of 31patients undergoing surgery for the treatment of oral squamous cell carcinoma was carried out at Department of Oral \& Maxillofacial Surgery ,Dhaka Dental college \& hospital from May 2016 to July2017. Here 31 patients, of them male 13 and female 18 having 31 to 80 years age ranges of oral squamous cell carcinoma who underwent surgery and reconstruction were included in this study. All patients were referred to oncologist after surgery. Aim of this study was to assess the status of disease, to provide the patient surgical treatment as a first line therapy, to find out any post-operative complications.

\section{KEY WORDS:}

Oral squamous cell Carcinoma, Oral cancer surgery, Mouth cancer treatment. 


\section{INTRODUCTION}

Cancer is a major cause of death throughout the world. Oral cancer is any malignant neoplasm, which is found on the lip, floor of the mouth, cheek lining, gingiva, palate or in the tongue. Oral cancer represents the third most common form of malignancy in the developing countries, whilst in the developed countries it is the eighth most common form of cancer ${ }^{1}$. Oral squamous cell carcinoma (OSCC) is the most frequent mouth accounting to $95 \%$ of all oral malignant lesions ${ }^{3}$.Smoking, betel quid, and tobacco-chewing habits are the factors, which cause high incidence in vast population in south East Asia ${ }^{5}$.

The factors that influence the choice of initial treatment are those related to the characteristics of the primary tumor, those related to the patient and those related to the treatment. The tumor factors that affect the choice of initial treatment of oral cancer are primary site, size ( $T$ stage), location (anterior versus posterior), proximity to bone (mandible or maxilla), status of cervical lymph nodes, previous treatment and histology (type, grade and depth of invasion). Several factors relative to patient characteristics are crucial in the selection of initial treatment of oral cancer. These are patient's age, general medical condition, tolerance of treatment, occupation of patient, acceptance and compliance by the patient, lifestyle (smoking and drinking) and other socioeconomic considerations. Surgery is the most well established mode of initial definitive treatment for a majority of oral cancer. ${ }^{4}$

Knowledge of the varied presentation and an experienced eye can go a long way in preventing the high morbidity and mortality associated with oral cancer. The percentage of 5year survival for patients with OSCC varies from $40-50 \%$. The aim of study is to assess the status of disease, to provide the patient surgical treatment as a first line therapy, to find out any post-operative complications and to find out any further problem \& solve them by other multidisciplinary approach.

\section{MATERIALS AND METHODS}

A cross sectional study of 31 patients histologically diagnosed oral squamous cell carcinoma attending at oral \& maxillofacial surgery department of Dhaka Dental College Hospital in period of May 2016 to July 2017 who underwent surgery that is wide excision of the lesion with radical or modified neck dissections with or without reconstruction .Exclusion criteria's were patients who are diagnosed as stage $1 \mathrm{Vc}$ oral squamous carcinoma, patients who referred to oncology dept. to treat them radiotherapy as a first line of treatment. Basic demographic data including age, gender, tumor location, tumor staging and reconstruction of surgical defects were documented.

\section{RESULTS:}

A total of 31 cases of OSCC reported during the study period treated with primary resection and neck dissection. Age of the patients ranged from 31 to 80years with a mean age of 56.79 years(Table-1 ) Sex distribution of patients were male13 persons (41.93\%)female18 patients (58\%) (Figure-1). Most common site for occurrence of oral squamous cell carcinoma in our study was buccal mucosa $5(16.1 \%)$ then tongue $4(12.9 \%)$,other sites were retro molar area, cheek, palatal mucosa, floor of the mouth etc. described in table. (Table-2 )All the patients were underwent surgery as a first line of treatment; that is wide excision of the lesion with radical or modified neck dissections. Only one patients had de bulking surgery. 19 (61.29\%) patients had primary closure, 5(16.12\%) patients with pectoralis mayo cutaneous flap, 6(19.35\%) patients with buccal pad of fat $\&$ in one(3.22\%) patient reconstruction was done by nasolabial flap.(Figure-2).All patients were referred to oncologist for radiotherapy.

Figure 1: Sex distribution of the respondents $(n=31)$

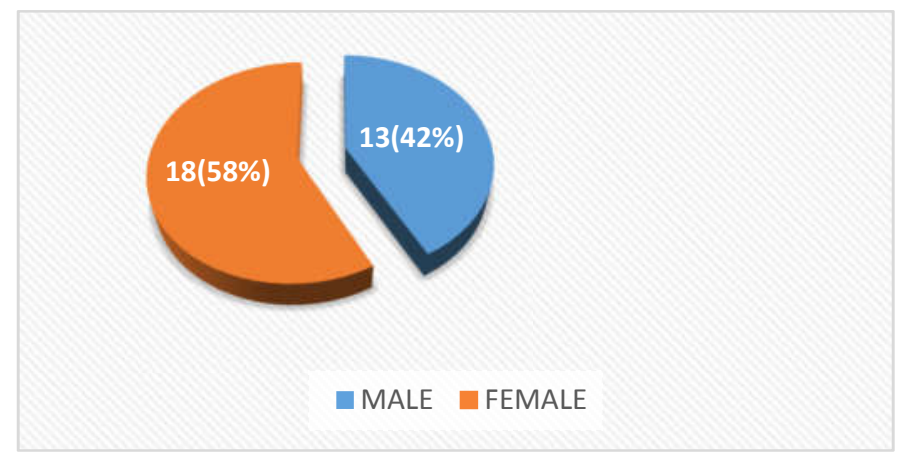

Figure illustrates the sex distribution of the respondents. Out of 31 patients $13(42 \%)$ were male and $18(58 \%)$ were female respondents.

Figure-2: Reconstruction of surgical defects $(n=31)$

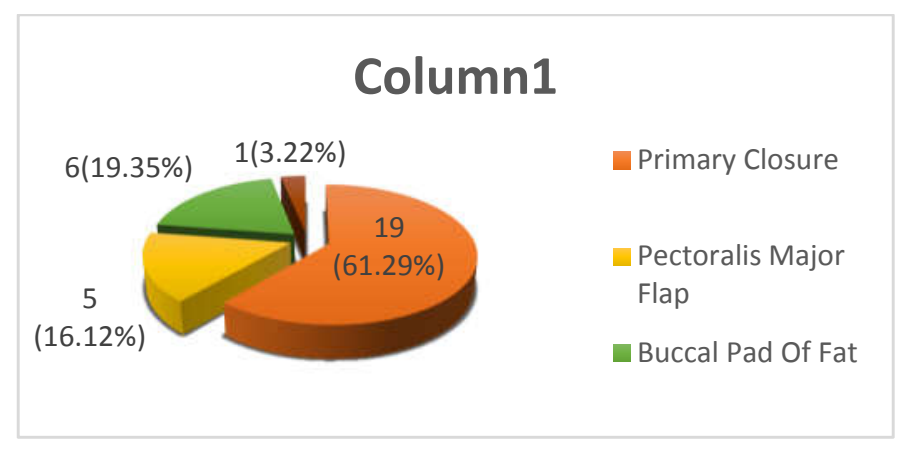

Figure shows reconstruction of surgical defects ( $n=31$ ).Majority $19(61.29 \%)$ patients by primary closure then $6(19.35 \%)$ patients by pectoralis major flap and $1(3.22 \%)$ patient by nasolabial flap. 
Table -1 : Age of the patients $(n=31)$

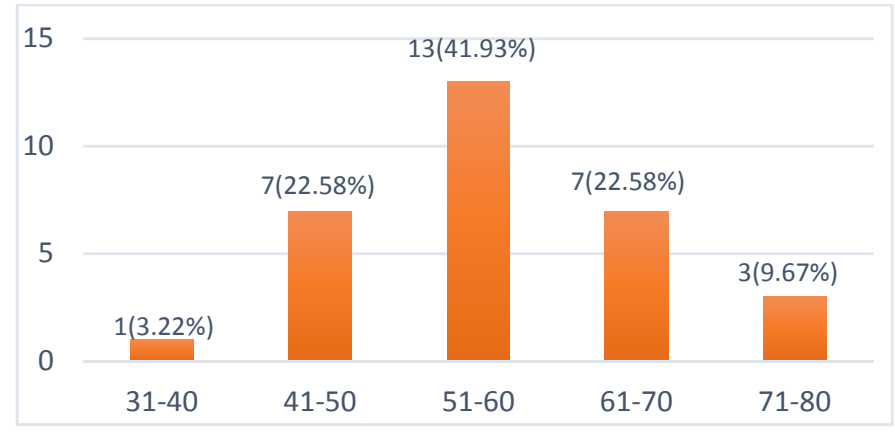

Table shows $41.93 \%$ population in the age group of $51-60$ years which was the most common 41.

Table -2: Site of incidence of oral squamous cell carcinoma ( $n=31)$

\begin{tabular}{|l|l|}
\hline \multicolumn{1}{|c|}{ Site } & Number \\
\hline Buccal mucosa & $4(12.9 \%)$ \\
\hline Retromolar area & $2(6.45 \%)$ \\
\hline Cheek & $3(9.67 \%)$ \\
\hline Palatal mucosa & $4(12.90 \%)$ \\
\hline Maxillary Tuberosity & $2(6.45 \%)$ \\
\hline Tongue & $5(16.1 \%)$ \\
\hline Floor of the mouth & $2(6.45 \%)$ \\
\hline Gingiva & $3(9.67 \%)$ \\
\hline Involving more than one site & $6(19.35 \%)$ \\
\hline Total & $\mathbf{3 1}(\mathbf{1 0 0} \%)$ \\
\hline
\end{tabular}

Table shows the site of incidence of oral squamous cell carcinoma. Major site was the tongue $5(16.1 \%)$ then buccal mucosa $4(12.9 \%)$ other site of incidence described in table.

Table-3: Staging of respondents $(n=31)$

\begin{tabular}{|c|c|c|c|}
\hline \multicolumn{2}{|c|}{ Stage } & \multicolumn{2}{|c|}{$\begin{array}{c}\text { Number of patients } \\
\text { (Percentage) }\end{array}$} \\
\hline \multicolumn{2}{|c|}{ Stage III } & \multicolumn{2}{|c|}{$11(35.48 \%)$} \\
\hline \multirow{2}{*}{ Stage IV } & IVa & $12(38.71 \%)$ & \\
\cline { 2 - 3 } & IVb & $8(25.81 \%)$ & \multirow{2}{*}{$64.52 \%$} \\
\cline { 2 - 3 } & IVc & 0 & \\
\cline { 2 - 3 } & & & \\
\hline
\end{tabular}

Table shows $11(35.48 \%)$ patients were at stage iii \& 20(64.52\%) patients were in stage $4 a \& 4 b$.
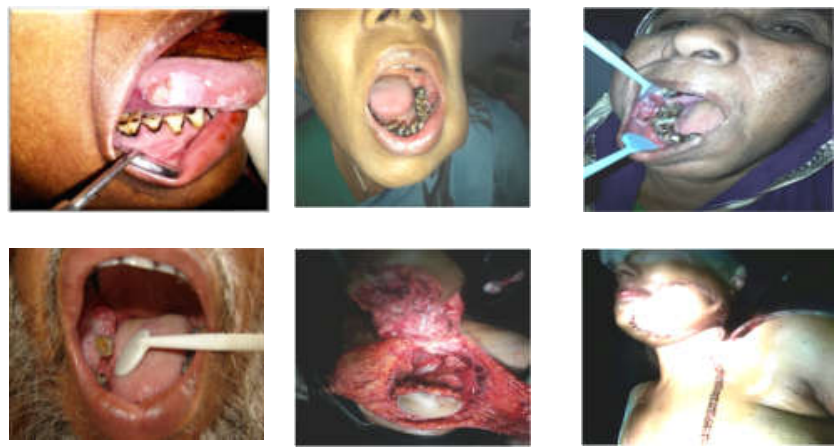

According to the serial from left to right in upper row Lesion at lateral border of tongue, lesion at right side of buccal mucosa, lesion at alveolar mucosa of mandible with skin invasion. In lower row, Lesion at right side of alveolar mucosa of mandible, Pectoralis major myocuteneous, Flap before placement, Pectoralis major myocucenous flap reconstruction

\section{DISCUSSION:}

Surgery is the most well established mode of initial definitive treatment for a majority of oral cancers, with a longstanding history of being the accepted method of treatment for well over a century. However, in the majority of patients with advanced cancer, radiotherapy is employed in conjunction with surgery, most often offered as post-operative treatment. Chemotherapy in the management of oral carcinoma was considered palliative in the 1950's, 60's and 70's. However with the introduction of Cis-platinum, clinical trials of induction chemotherapy demonstrated that response to chemotherapy was observed in a significant number of patients. However, unlike other sites in the head and neck area, the response to induction chemotherapy did not translate into long term control of primary oral squamous cell carcinomas. ${ }^{4}$

The present study mean age of occurrence was $56.79 y e a r s$. Predictably in our study, the most affected age group was 51-60 years. According to US National Cancer Institute SEER program the mean age of diagnosis of oral cancer is 65 years. Sankaranarayan et al. found that the peak age frequency of occurrence in India is at least a decade earlier than that described in the western literature ${ }^{7}$. Gupta et al observed an increase in the incidence of oral cancer in the younger (less than 50 years) age group ${ }^{8}$.

The male female ratio (1:1.38) was almost same like most of the other studies. Pinhold et al .observed almost equivalent numbers between men and women $(1.2: 1)^{9}$. There is significant bias in the incidence of oral cancer amongst males, which can be attributed to the easy acceptance of habits by males the habits of tobacco and betel nut as a means of stimulants renders males more susceptible to oral cancers. 
The present study shows incidence rate of Buccal Mucosa was higher (16.1\%). TheTongue is considered the most common site for carcinoma in the oral cavity according to western literature by Watkinson. ${ }^{10}$ But a study by shaheed ${ }^{2}$ showed Buccal mucosa(58\%) much higher incidence rate in Bangladesh.In our study regarding staging about $11(35.48 \%)$ patients were diagnosed as stagellI\& 20(64.52\%) patients were in stage $4 a \& 4 b . R U$ Danish ${ }^{11}$ observed in total of 60 cases , $46(76.66 \%)$ patients presented with stage IV disease while $14(23.33 \%)$ patients presented with stage III disease .Most patients (346/703:49.2\%) had stage Illcancer by Chen YK. ${ }^{12}$

Reconstructive surgery following resection for oral cancer is considered when there is functional or aesthetic loss of structures in the oral cavity. ${ }^{13}$ There is a wide range of reconstructive options for composite hard tissue defects. Depending on the particulars of the defect, planned outcome, donor-site morbidity and the individual surgeon's training and experience, several methods of reconstruction may be available. In general, the best option is the simplest one that is primary closure of the defect will enable all the functional and esthetic goals of reconstruction to be met. ${ }^{14}$ Our study represents the same result while most of the patients treated by primary closure $19(61.29 \%)$.

At present, pectoralis major myocutaneous flap described by Aryan(1978) is still the "Work Horse" for most head and neck reconstruction. ${ }^{14}$ Pectoralis major myocutaneous flap in 4 cases/out of 30 by was done Madhumati S. ${ }^{14}$ Present study we performed 6cases out of 31 by pectoralis major myocutaneous flap reconstruction. Buccal fat pad are raid reepitheliazation, rich vascular supply. ${ }^{15}$ We performed 6 cases by buccal fat pad reconstruction but a review study by Madhumati S. ${ }^{15}$ showed 1 case out of 12 buccal pad reconstruction. Nasolabial flap cover large amount of tissue and good cosmetic result following closure of donor site. ${ }^{15} \mathrm{We}$ performed 1 case by nasolabial flap reconstruction and a review study by Madhumati $\mathrm{S}^{15}$ showed 1 case out of 12 nasolabial flap reconstruction.

Primary surgical excision of malignant neoplasms of the skin, soft tissues and bone remains the mainstay of initial definitive treatment. The details of surgical procedures arising in these tissues are so wide that it is not possible to cover the entire spectrum of these neoplasms in this manuscript. In general, however, whenever feasible a wide three-dimensional resection securing negative margins remains the mainstay of appropriate surgery. When indicated, immediate reconstruction is embarked upon, particularly for large soft tissue and skin defects and for bony defects affecting the framework of the face. In general regional myocutaneous flaps and free tissue transfer remain the essential modalities for immediate reconstruction of such defects.

\section{CONCLUSION}

Surgery thus remains the mainstay of management of a majority of neoplasms arising in the head and neck area. The role of the surgeon begins from making the initial clinical diagnosis, assessing the extent of the tumor for proper staging and obtaining tissue by biopsy for confirmation of histologic diagnosis. ${ }^{4}$ It is imperative to emphasize at this point that head and neck surgery is a specialty which requires dedicated additional training following basic surgical training in general surgery, otolaryngology, plastic surgery or maxillofacial surgery. ${ }^{4}$ Thus, a head and neck surgical oncologist is an individual who has surgical expertise along with knowledge and familiarity with the biological behavior of the cancer and the appreciation of the importance of multidisciplinary treatment.

\section{REFERENCES:}

1.Moore SR, Johnson NW, Pierce AM, Wilson DF. The epidemiology of mouth cancer: a review of global incidence. Oral Dis. 2000;6:65-74. https://doi.org/10.1111/j.1601-0825.2000.tb00104.x PMid:10702782

2. Shaheed I and Molla MR. Oral cancer in Bangladesh; Its aetiology and histological grading. J of Oral Health.1996 Apr;2(2):8-11.

3. Sankaranarayanan R. Oral cancer in India: a clinical and epidemiological review. Oral Surg Oral Med Oral Pathol. 1990;69:325-330. https://doi.org/10.1016/0030-4220(90)90294-3

4. Shah JP andGilZ.Current concepts in management of oral cancer surgery. Oral Oncology 2009;45:394-401.

https://doi.org/10.1016/j.oraloncology.2008.05.017

PMid:18674952 PMCid:PMC4130348

5. Bhurgi Y. Cancer of the oral cavity - trends in south Karachi (1995 2002). Asian Pac. J. Cancer Prev. 2005; 6 (1) :22-26.

6. Rahman SS, Sarker MK, Khan MH, Biswas SS, Saha MM. Clinical profile of oral squamous cell carcinoma patients attending a tertiary care hospital.Bang Med J Khulna 2014; 47 : 3-6.

https://doi.org/10.3329/bmjk.v47i1-2.22554

7. Sankaranarayan F. Oral cancer in India, an epidemiological and clinical review. Oral Surg Oral Med Oral Pathol 1990; 69: 325-30. https://doi.org/10.1016/0030-4220(90)90294-3

8. Gupta PC, Murti PR, Bhonle RB, Mehta FS, Pindborg J. Effect of cessation tobacco use. Oral DIS 1995; 1:54-8.

https://doi.org/10.1111/i.1601-0825.1995.tb00158.x PMid:7553382

9.. Pinholt EM, Riindurn J, Pindborg JJ. Oral Cancer: A retrospective study of 100 Danish cases. Br J oral Maxillofac Surg 1997; 35: 77-80.

https://doi.org/10.1016/S0266-4356(97)90679-3

10. Watkinson CJ, Gaze MN, Wilson JA. Tumours of the lip and oral cavity. In: Stell and Maran's head and neck surgery. 4th edn. Oxford, Butterworth-Heinemann;2000. pp.275-318.

11. Danish RU, Hafeez SH, Zeba A, Muhammad MS. Frequency of Cervical Metastasis in Oral Cancer.Pakistan Journal of Otolaryngology 2013; 29 : 80-83.

12 .Chen KY, Huang CH, lin ML, Lin C. Primary oral squamous cell carcinoma:an analysis of 703 cases in southern Taiwan.Oral Oncology 2009;45(0): 394-401.

13.Shah PJ and Gill Z.Current concepts in management of oral cancer surgery. Oral Oncology 2009; 45(0): 394-40.

https://doi.org/10.1016/j.oraloncology.2008.05.017

PMid:18674952 PMCid:PMC4130348

14. Madhumati S, Anjan S, Amit B, Narahari B, R Ragesh, K Sandeep. Reconstruction of post-surgical defects after tumor resection: Our experience and review of 30 cases. Int J Contemp Dent Med Rev 2015;7 15. Madhumati S, Anjan S, Shouvik C.Versaile graftsandflaps in reconstruction of oral and maxillofacial postsurgical defects. International journal of head and neck surgery2011:2(1);11-25. 